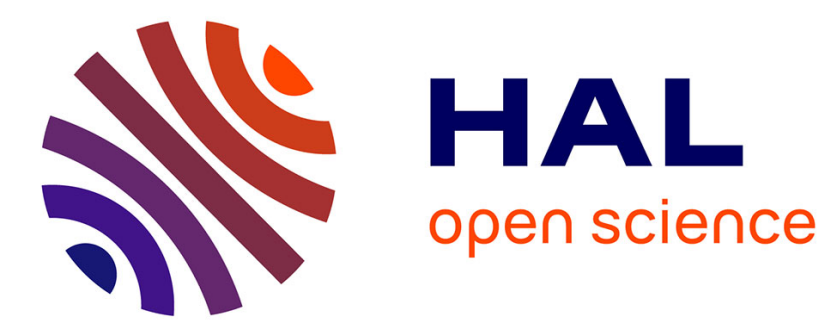

\title{
Risk aversion and the value of diagnostic tests
}

\author{
Hal Bleichrodt, David Crainich, Louis Eeckhoudt, Nicolas Treich
}

\section{To cite this version:}

Hal Bleichrodt, David Crainich, Louis Eeckhoudt, Nicolas Treich. Risk aversion and the value of diagnostic tests. Theory and Decision, 2020, 89 (2), pp.137-149. 10.1007/s11238-020-09750-8 . hal03048860

\section{HAL Id: hal-03048860 \\ https://hal.science/hal-03048860}

Submitted on 18 Oct 2021

HAL is a multi-disciplinary open access archive for the deposit and dissemination of scientific research documents, whether they are published or not. The documents may come from teaching and research institutions in France or abroad, or from public or private research centers.
L'archive ouverte pluridisciplinaire HAL, est destinée au dépôt et à la diffusion de documents scientifiques de niveau recherche, publiés ou non, émanant des établissements d'enseignement et de recherche français ou étrangers, des laboratoires publics ou privés. 


\title{
Risk aversion and the value of diagnostic tests
}

\author{
Han Bleichrodt \\ Erasmus School of Economics, Rotterdam \\ Research School of Economics, Australian National University, Canberra \\ David Crainich \\ CNRS, IESEG School of Management, Univ. Lille, UMR 9221 - LEM, F-59000 Lille

\section{Louis Eeckhoudt} \\ IESEG School of Management, UMR 9221 - LEM, F-59000 Lille \\ Nicolas Treich \\ Toulouse School of Economics, INRAE, University Toulouse Capitole, Toulouse
}

\begin{abstract}
Diagnostic tests allow better informed medical decisions when there is uncertainty about a patient's health status and, therefore, about the desirability to undertake treatment. This paper studies the relation between the expected value of diagnostic information and a patient's risk aversion. We show that the ex ante value of diagnostic information increases with risk aversion for diseases with low prevalence, but decreases with risk aversion for diseases with high prevalence. On the other hand, the ex post value of diagnostic information always increases with the patient's degree of risk aversion.
\end{abstract}

Keywords : Diagnostic risks; diagnostic tests; value of information; risk aversion. JEL classification: D80; I10

\section{Introduction}

The side effects of medical treatments may cause health deteriorations when they are administered to healthy patients. Diagnostic risk refers to situations in which a physician is uncertain about the true health state of a patient and whether treatment would be 
beneficial or harmful. Diagnostic tests eliminate (if they are perfect) or reduce (if they are imperfect) diagnostic risks.

The economic analysis of diagnostic tests was pioneered by Pauker and Kassirer (1980). They assessed the effectiveness of diagnostic tests by comparing the costs and benefits of the treatment decision when the test is performed with those accruing when the test is not performed. A more extensive analysis was performed by Eeckhoudt, Lebrun and Sailly (1984) who also considered the possibility of imperfect tests and developed a measure of the effectiveness of diagnostic tests. Both Pauker and Kassirer (1980) and Eeckhoudt, Lebrun and Sailly (1984) assumed that patients were neutral with respect to health risks. The descriptive validity of this assumption is questionable. Empirical research typically observes that people are averse towards health/life duration risks (McNeil et al. 1981, Stiggelbout et al 1994, Bleichrodt and Pinto 2005). To properly assess the costs and benefits of diagnostic tests, patients' risk attitudes should be taken into account.

Intuitively, one might conjecture that more risk averse patients will value diagnostic tests more, because these tests reduce uncertainty and protect against the risk of wrong treatment decisions. However, since Gould (1974), the literature on the value of information has shown that increases in risk and risk aversion do not necessarily increase the value of information. ${ }^{1}$ Eeckhoudt, Lebrun and Sailly (1985) showed that an increase in risk aversion may decrease the demand for diagnostic information when utility is of the constant absolute risk aversion (CARA) family. Eeckhoudt (2002) showed intuitively why the relationship between risk aversion and diagnostic information is non-monotonic. Diagnostic tests are useful if they reverse the decision that would be taken in the absence of such tests. However, if risk aversion becomes stronger a patient will be more inclined to take treatment even if the test result is negative and, hence, the value of information decreases. Finally, Felder and Mayrhofer (2014) showed that a risk averse decision makers (DM) will be more inclined to test than a risk neutral DM at lower disease prevalence but less inclined at higher disease prevalence. They also compared the effect of comorbidities and showed that this pattern of a higher inclination to test at low prevalence and a lower inclination to test at high prevalence was even more pronounced

${ }^{1}$ See for instance Freixas and Kihlstrom (1984) or Willinger (1989). A summary of the determinants of the value of information is provided in Hilton (1981). 
for risk vulnerable DMs. Risk vulnerability was introduced by Gollier and Pratt (1996) and it implies that DMs will want to reduce the risks that he can control in the presence of uncontrollable background risks. It requires that DMs are not only risk averse but also prudent (which is equivalent to a positive third derivative of their expected utility function) and temperate (which is equivalent to a negative fourth derivative of their expected utility function).

The above contributions indicate that the relation between risk aversion and the expected value of information is inverse U-shaped: up to a certain threshold increases in risk aversion increase the expected value of diagnostic information, but after that threshold they decrease it. However, this result has been obtained in special cases only: Eeckhoudt, Lebrun and Sailly (1984) showed it under CARA utility, Eeckhoudt (2002) used specific numerical examples, and Felder and Mayrhofer (2014) only compared the choices made by risk neutral and risk averse patients but did not consider the general effect of increases in risk aversion. Results that hold for the comparison between a risk neutral and a risk averse decision maker can typically not be generalized automatically to the comparison between a risk averse and a more risk averse DM, but require additional conditions. ${ }^{2}$ Moreover, these contributions adopted an ex ante approach to the value of information. In the ex ante approach a diagnostic test only derives value from the changes in treatment behavior that it induces. It has no value per se but only through the decision it implies. However, by revealing the state of the world, the test also removes the risk patients are exposed to, which a risk averse DM values. The ex post approach captures both this additional benefit and the opportunity to make a better-informed treatment decision.

This paper makes two contribution. First, we generalize Eeckhoudt et al. (1985), Eeckhoudt (2002), and Felder and Mayrhofer (2014) and derive a general result about the relationship between risk aversion and the ex ante value of perfect information. We show that the value of information may decrease when the degree of risk aversion increases and we give a formal proof of this result. Second, we show that in the ex post approach, which captures both benefits of diagnostic tests and which has not been

\footnotetext{
${ }^{2}$ See for example Sandmo (1971) and Ebert et al. (2018).
} 
explored in the health literature yet, the expected value of diagnostic tests always increases with the degree of risk aversion.

Our paper is organized as follows. Assumptions and notations are introduced in section 2. Treatment decisions in the absence of diagnostic information are described in section 3. The effect of risk aversion on the ex ante and ex post values of the diagnostic information are analyzed in sections 4 and 5 respectively. Section 6 concludes.

\section{Assumptions and notation}

We consider patients exposed to diagnostic risk. The patients can either be sick or healthy. Their probability of disease is denoted by $p$. We assume that the patients' health can be measured on an interval scale, for example by the number of QALYs. In case of disease and in the absence of treatment, the patients' health is $h_{0}$. If they are not sick (which occurs with probability $1-p$ ) and in the absence of treatment, their health is $h_{1}$ with $h_{1}>h_{0}$. When sick patients receive treatment, their health improves to $h_{0}+b, b>0$. When healthy patients receive treatment their health deteriorates to $h_{1}-c, c>0$. We assume that treatment can never make a healthy patient worse off than a sick patient and, therefore, $h_{0}+b<h_{1}-c$.

The patients' decision problem is summarized in the following table: ${ }^{3}$

Table 1: The patients' decision problem

\begin{tabular}{|l|cc|}
\hline \multirow{2}{*}{ No treatment } & Sick & Healthy \\
\cline { 2 - 3 } Treatment & $h_{0}$ & $h_{1}$ \\
& $h_{0}+b$ & $h_{1}-c$ \\
\hline
\end{tabular}

Patients maximize their expected utility and their preferences over health states are represented through the utility function $u(h)$, which is increasing $\left(u^{\prime}(h)>0\right)$ and concave $\left(u^{\prime \prime}(h)<0\right)$. Bleichrodt and Pinto (2005) provide support for these assumptions and show that utility is indeed increasing and concave for years in good health, years with migraine, and years with back pain.

\footnotetext{
${ }^{3}$ If a physician acts on behalf of the patients we assume that the physician is perfectly benevolent and acts
} fully in agreement with the patients' interests. 


\section{Treatment decision in the absence of a test}

The value of diagnostic information depends on a comparison of the decision with and without the test. In this Section we first examine the patient's treatment decision and the effect of risk aversion on this decision in the absence of a diagnostic test. The decision with the test will be explored in the next Section.

If patients decide to take no treatment their expected utility is $(1-p) u\left(h_{1}\right)+p u\left(h_{0}\right)$. If they decide to take treatment it is $(1-p) u\left(h_{1}-c\right)+p u\left(h_{0}+b\right)$. Treatment is beneficial when patients are sick and the higher the prevalence of disease $(p)$ the more inclined they are to take treatment. The treatment threshold (denoted by $\hat{p}_{u}$ where the subscript $u$ indicates that the patients have utility function $u$ ) is defined as the prevalence at which the patients are indifferent between treatment and no treatment:

$$
\left(1-\hat{p}_{u}\right) u\left(h_{1}\right)+\hat{p}_{u} u\left(h_{0}\right)=\left(1-\hat{p}_{u}\right) u\left(h_{1}-c\right)+\hat{p}_{u} u\left(h_{0}+b\right)
$$

From Eq. (1), the treatment threshold is equal to:

$$
\hat{p}_{u}=\frac{u\left(h_{1}\right)-u\left(h_{1}-c\right)}{\left[u\left(h_{0}+b\right)-u\left(h_{0}\right)\right]+\left[u\left(h_{1}\right)-u\left(h_{1}-c\right)\right]}
$$

Consider next a more risk averse patient whose utility function $v$ is a concave transformation of $u$. The treatment threshold (denoted $\hat{p}_{v}$ ) of this more risk averse patient is given by:

$$
\hat{p}_{v}=\frac{v\left(h_{1}\right)-v\left(h_{1}-c\right)}{\left[v\left(h_{0}+b\right)-v\left(h_{0}\right)\right]+\left[v\left(h_{1}\right)-v\left(h_{1}-c\right)\right]}
$$

From theorem 1 in Pratt (1964), it can be shown that:

Result 1: For all utility functions $u$ and $v, \hat{p}_{u}>\hat{p}_{v}$ if and only if $-\frac{v^{\prime \prime}}{v^{\prime}}>-\frac{u^{\prime \prime}}{u^{\prime}}$.

In words, result 1 says that patients whose risk aversion, as measured by the Arrow-Pratt coefficient, is higher are more treatment prone since they accept treatment at lower 
probabilities of disease. This result can be explained as follows. By taking the treatment, patients reduce the spread of their health prospects from $h_{1}-h_{0}$ to $\left(h_{1}-c\right)-\left(h_{0}+b\right)$. The more risk averse patients are, the more they value this reduction in spread. The benefit of the treatment is thus higher for more risk averse patients who will, consequently, take it at lower probabilities of disease (Eeckhoudt 2002).

\section{The ex ante value of diagnostic information}

Suppose now that a diagnostic test is available which can detect the disease among sick patients. We assume that the test is perfect. ${ }^{4}$ In this section we consider the ex ante value of the diagnostic information: the expected gain because the test allows making the best treatment decision. Because utility is defined over health, the value of information is measured by the health (the number of QALYs) patients are willing to sacrifice to obtain the information. To measure the patient's willingness to pay for the diagnostic information requires specifying a two-attribute utility function, which would complicate the analysis as cross-product derivatives would be involved (Eeckhoudt, Rey, and Schlesinger 2007). We leave these complications for future research.

\subsection{The ex ante value of diagnostic information and disease prevalence}

When the probability of disease is lower than $\hat{p}_{u}$, patients choose not to take treatment. In that case the diagnostic test has value if it indicates that the patients actually have the disease and they reverse their treatment decision. The expected value of the diagnostic test is then equal to $r_{u}$ as defined by Eq. (4):

$$
(1-p) u\left(h_{1}-r_{u}\right)+p u\left(h_{0}+b-r_{u}\right)=(1-p) u\left(h_{1}\right)+p u\left(h_{0}\right)
$$

Because $u$ is increasing, $r_{u}<b$. Therefore, $h_{0}<h_{0}+b-r_{u}<h_{1}-r_{u}<h_{1}$. We now show the following:

Result 2: Let $p<\hat{p}_{u}$. Then $r_{u}$, the ex ante value of diagnostic information when no treatment would be chosen in the absence of the test, increases with $p$.

\footnotetext{
${ }^{4}$ Allowing for imperfect tests would complicate the analysis and requires using different concepts of risk aversion. We leave this for future research.
} 


\section{Derivation:}

By the implicit function theorem:

$$
\frac{d r_{u}}{d p}=\frac{u\left(h_{0}+b-r_{u}\right)-u\left(h_{1}-r_{u}\right)+u\left(h_{1}\right)-u\left(h_{0}\right)}{(1-p) u^{\prime}\left(h_{1}-r_{u}\right)+p u^{\prime}\left(h_{0}+b-r_{u}\right)}=\frac{A}{B}>0
$$

Expression A is positive because the negative difference $u\left(h_{0}+b-r_{u}\right)-u\left(h_{1}-r_{u}\right)$ is more than offset by the positive term $u\left(h_{1}\right)-u\left(h_{0}\right)$. Expression B is positive because $u$ is increasing. Hence, $r_{u}$ increases with $p$.

The explanation why the ex ante expected value of information increases with the probability of disease is as follows. When $p<\hat{p}_{u}$, treatment is not performed in the absence of the test. A diagnostic test leads to a gain if it reverses the no treatment decision and a sick patient is now treated. This occurs if the test reveals that the patient is sick, i.e. with probability $p$. The higher is $p$ the more likely it is that the test has value and, therefore, the value of the test increases with $p$.

Suppose next that the probability of disease exceeds $\hat{p}_{u}$. Then treatment is performed in the absence of a test and the test has value if it indicates that the patient is healthy and no treatment is required. The expected value of the diagnostic information is given by $s_{u}$ in Eq. (6):

$$
(1-p) u\left(h_{1}-s_{u}\right)+p u\left(h_{0}+b-s_{u}\right)=(1-p) u\left(h_{1}-c\right)+p u\left(h_{0}+b\right) .
$$

Because $u$ is increasing, we must have $s_{u}<c$. Therefore, $h_{0}+b-s_{u}<h_{0}+b<h_{1}-c<$ $h_{1}-r_{u}$

Result 3: Let $p>\hat{p}_{u}$. Then $s_{u}$, the ex ante value of diagnostic information when treatment would be chosen in the absence of the test, decreases with $p$.

\section{Derivation:}

The proof is very similar to the proof of Result 2. By the implicit function theorem: 


$$
\frac{d s_{u}}{d p}=\frac{u\left(h_{0}+b-s_{u}\right)-u\left(h_{1}-s_{u}\right)+u\left(h_{1}-c\right)-u\left(h_{0}+b\right)}{(1-p) u^{\prime}\left(h_{1}-s_{u}\right)+p u^{\prime}\left(h_{0}+b-s_{u}\right)}=\frac{C}{D}<0
$$

Expression $C$ is negative because the negative difference $u\left(h_{0}+b-s_{u}\right)-u\left(h_{1}-s_{u}\right)$ cannot be compensated by the positive term $u\left(h_{1}-c\right)-u\left(h_{0}+b\right)$. Expression D is positive because $u$ is increasing. Hence, $s_{u}$ decreases with $p$.

When $p>\hat{p}_{u}$ the test creates a gain when it reverses the treatment decision for a healthy person. This happens with probability $1-p$. As $p$ increases this gain becomes more and more unlikely and so the value of diagnostic information when treatment is the default choice falls with $p$.

Results 2 and 3 show that the value of information increases with $p$ up to the treatment threshold and then drops. We have derived this for a risk averse patient, but it also holds for risk seeking and risk neutral patient. Under risk neutrality the treatment threshold is

given by $\hat{p}_{n}=\frac{c}{b+c}$ and the expected value of the diagnostic information is given by:

$$
\left\{\begin{array}{c}
r_{n}=p b \quad \text { if } p \in\left[0, \hat{p}_{n}\right] \\
s_{n}=(1-p) c \quad \text { if } p \in\left[\hat{p}_{n}, 1\right]
\end{array}\right.
$$

\subsection{The effect of risk aversion on the ex ante value of diagnostic information}

In this Section we show the following result:

Result 4: Consider two patients with utility functions $v$ and $u$ with $v$ more risk averse (concave) than $u$. There is a unique crossing point $p_{c} \in\left(\hat{p}_{v}, \hat{p}_{u}\right)$ up to which the value of the diagnostic test increases with risk aversion and after which it falls with risk aversion.

\section{Derivation:}

For ease of exposition we call patients with utility function $v$, patients $v$, and patients with utility function $u$, patients $u$.

If $p<\hat{p}_{v}$, the expected value of the diagnostic information when no treatment is chosen (denoted by $r_{v}$ ) of patients $v$ is equal to: 


$$
(1-p) v\left(h_{1}-r_{v}\right)+p v\left(h_{0}+b-r_{v}\right)=(1-p) v\left(h_{1}\right)+p v\left(h_{0}\right)
$$

Denote by $\tilde{x}$ and $\tilde{y}$ the distributions: $\tilde{x}={ }_{d}\left(h_{0}+b, p ; h_{1}, 1-p\right)^{5}$ and $\tilde{y}={ }_{d}\left(h_{0}, p ; h_{1}, 1-\right.$ $p$ ). Distribution $\tilde{x}$ corresponds to the situation in which patients $v$ have the diagnostic information (and take treatment only when they are sick). Distribution $\tilde{y}$ corresponds to the situation where patients do not have the diagnostic information and choose not to take treatment since $p<\hat{p}_{v}$.

From Eq. (4), which describes the value of information for patients $u$, we know that the distributions $\tilde{x}-r_{u}$ and $\tilde{y}$ yield the same expected utility for patients $u$. The cumulative distributions of $\tilde{x}-r_{u}$ and $\tilde{y}$ are depicted in figure 1 .

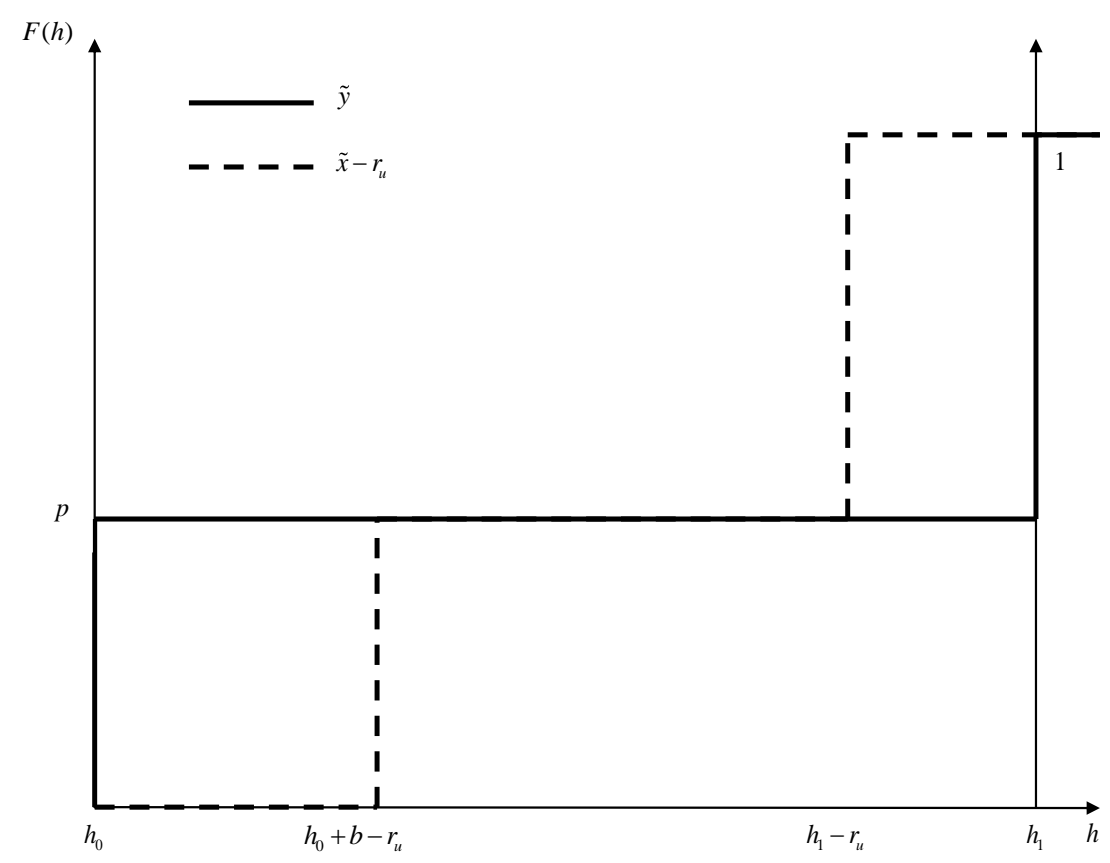

Figure 1: Cumulative distributions with $\left(\widetilde{x}-r_{u}\right)$ and without $(\widetilde{y})$ a diagnostic test when no treatment is chosen in the absence of a test.

Because $r_{u}<b$, the cumulative distribution $\tilde{x}-r_{u}$ crosses the cumulative distribution $\tilde{y}$ once from below. By Theorem 1 in Jewitt $(1987)^{6}$ and the fact that $u$ is less risk averse

\footnotetext{
${ }^{5}$ This stands for obtaining health state $h_{0}+b$ with probability $p$ and health state $h_{1}$ with probability $1-p$. ${ }^{6}$ Theorem 1 in Jewitt $(1987$, p.75) is as follows: Let the distribution functions $F$ and $G$ cross exactly once, and suppose that $G$ crosses $F$ from below. It follows that $\int u d G \geq \int u d F$ implies $\int v d G \geq \int v d F$ whenever $u$ and $v$ are both increasing with $v$ more risk averse than $u$ in the sense of Arrow-Pratt.
} 
than $v$, we obtain $E\left[v\left(\tilde{x}-r_{u}\right)\right] \geq E[v(\tilde{y})]$. By Eq. (9) it then follows that $r_{u}<r_{v}$. In other words, when the prevalence of the disease is lower than $\hat{p}_{v}$, the value of diagnostic information is higher for patients who are more risk averse in the sense of Arrow-Pratt.

Suppose now that $p>\hat{p}_{u}$. The value $s_{v}$ that patients $v$ assign to the diagnostic information when treatment is the default choice is equal to:

$$
(1-p) v\left(h_{1}-s_{v}\right)+p v\left(h_{0}+b-s_{v}\right)=(1-p) v\left(h_{1}-c\right)+p u\left(h_{0}+b\right)
$$

Define the distribution: $\tilde{z}={ }_{d}\left(h_{0}+b, p ; h_{1}-c, 1-p\right)$. Distribution $\tilde{z}$ corresponds to the situation in which the patient does not have the diagnostic information and chooses to take treatment.

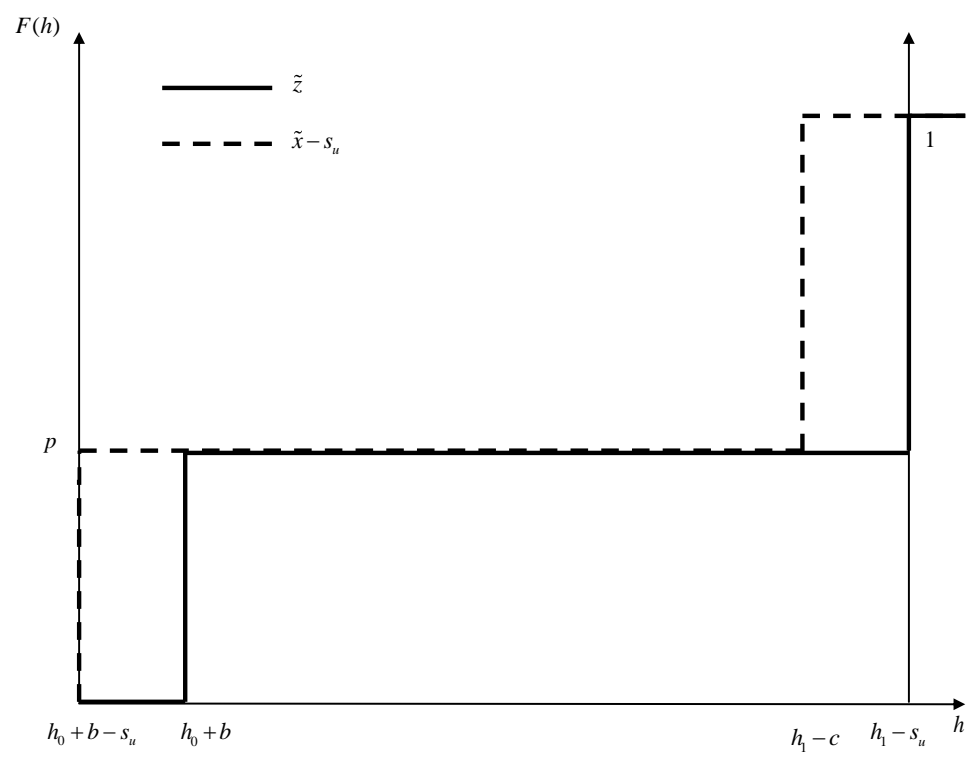

Figure 2: Cumulative distributions with $\left(\tilde{x}-s_{u}\right)$ and without $(\tilde{z})$ a diagnostic test when treatment is chosen in the absence of a test.

Figure 2 shows that the cumulative distribution of $\tilde{z}$ crosses the cumulative distribution of $\tilde{x}-s_{u}$ once from below (since $s_{u}<c$ ). Again, by Theorem 1 in Jewitt (1987), $E\left[v\left(\tilde{x}-s_{u}\right)\right] \leq E[v(\tilde{z})]$, because $v$ is more risk averse than $u$. From Eq. (10), we then obtain $s_{u}>s_{v}$. Consequently, for disease probabilities larger than $\hat{p}_{u}$, the expected value 
of the diagnostic information is lower for patients who are more risk averse in the sense of Arrow-Pratt.

Using Results 1 to 4, Figure 3 displays how the ex ante expected value of information changes with the disease probability for patients $u$ and $v$. Denote the value of information of patients $u$ and $v$ as $V I_{u}$ and $V I_{v}$. Whenever $p<\hat{p}_{v}$, patients $v$ do not take treatment in the absence of a test and their health is either $h_{0}$ or $h_{1}$ (with probabilities $p$ and $1-p$, respectively). If a diagnostic test is performed, the treatment is taken only if patients $v$ are sick, so that their final health is either $h_{0}+b$ or $h_{1}$ (also with probabilities $p$ and $1-p$, respectively). The benefits of taking the test are thus twofold. On the one hand, the test increases the average health state by $p b$. On the other hand, by improving the worse health state, the diagnostic test reduces the dispersion of the health distribution. This reduction in dispersion is particularly valued by more risk averse patients, so that $V I_{v}>$ $V I_{u}$ if $p<\hat{p}_{v}$.

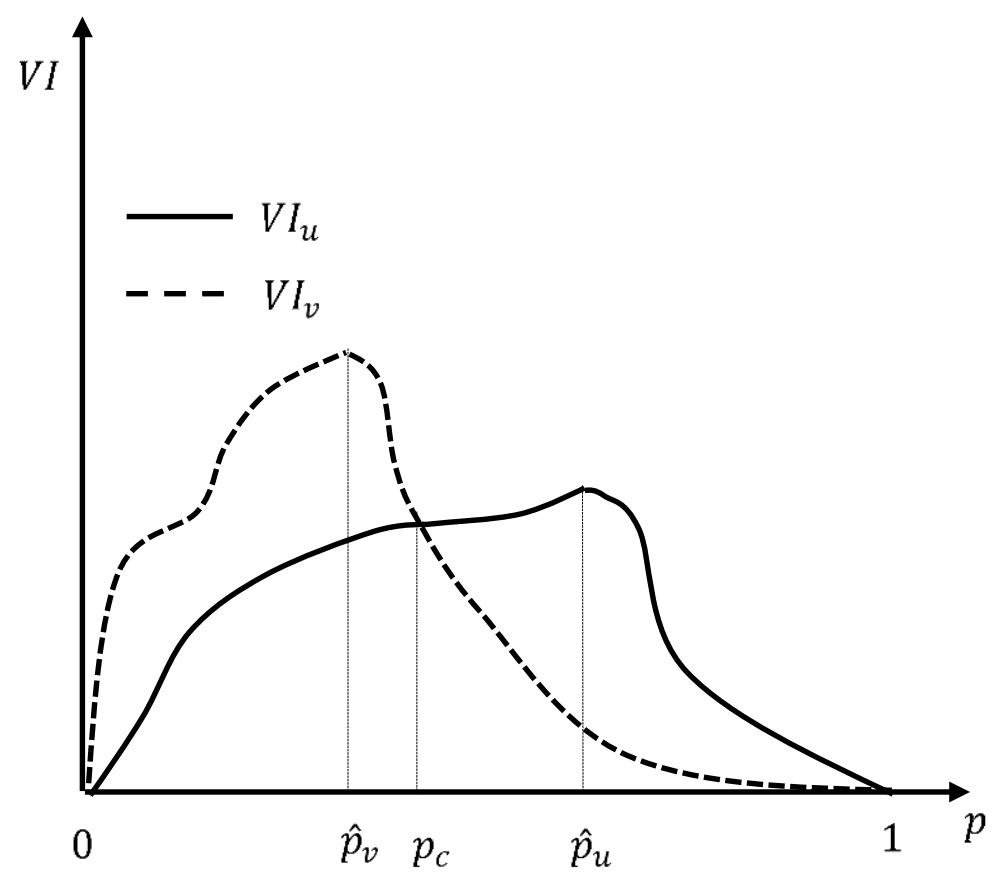

Figure 3: Value of information for patients $\mathrm{u}$ and $\mathrm{v}$ as a function of disease probability $\mathrm{p}$

A similar interpretation can be used if the probability of disease exceeds $\hat{p}_{u}$. Then all patients take treatment in the absence of a test. If they perform the test, they take the 
treatment only if they are sick and they switch from health distribution $\left(h_{0}+b, p ; h_{1}\right.$ $c, 1-p)$ to health distribution $\left(h_{0}+b, p ; h_{1}, 1-p\right)$. The test thus increases average health by $(1-p) c$, which is valued by all patients. But, in this case, by improving the better outcome, the test also increases the dispersion of the health distribution. This effect of the test is disliked by risk averse patients and the more so the stronger is their risk aversion. Consequently, we obtain: $V I_{v}<V I_{u}$ if $p>\hat{p}_{u}$.

Finally, let us look at what happens in the interval $\left(\hat{p}_{v}, \hat{p}_{u}\right)$. We know that risk aversion increases the ex ante value of information of both patients if $p<\hat{p}_{v}$ and decreases the ex ante value of information of both patients if $p>\hat{p}_{u}$. Moreover we know that at $\hat{p}_{v}, V I_{v}>$ $V I_{u}$ and from Results 2 and 3 that for $p \in\left(\hat{p}_{v}, \hat{p}_{u}\right), V I_{v}$ decreases and $V I_{u}$ increases. As a result, $V I_{v}$ and $V I_{u}$ can only cross once at a specific probability of disease $p_{c} \in\left(\hat{p}_{v}, \hat{p}_{u}\right)$. Moreover, as $V I_{\mathfrak{z}}$ falls at an increasing rate and $V I_{\mathcal{t}}$ rises at a decreasing rate this crossing probability is less than $\frac{\hat{p}_{v}+\hat{p}_{z}}{z}{ }^{7}$-This implies that increases in risk aversion increase the value of information if and only if the prevalence probability $p$ is below $p_{c}$ and that they reduce the value of information above $p_{c}$.

\section{The ex post value of diagnostic information}

The ex ante value of diagnostic information is based on the comparison between the situations with and without information, but before disclosure of the test result, which is not taken into account. So it is based on a comparison between two risky situations. The ex post approach takes disclosure of the test result into account and includes the welfare gain that patients experience when the test shows that they are healthy and the welfare loss they experience when the test shows that they are sick. The ex post approach thus compares the initial risky situation (with no information) with the two certain states the patients may end up with if they take the test. Then the question is whether the test leads to an overall increase in welfare, i.e. whether the potential welfare gain of revealing that patients are healthy outweighs the potential welfare loss of revealing that they are sick. The ex ante and ex post approach both include the benefit of better informed medical decisions, but only the ex post approach includes the benefit of removing the risk. The next result shows how risk aversion affects the ex post value of the diagnostic information.

\footnotetext{
${ }^{7}$ For a risk neutral patient it is exactly equal to $\frac{\hat{p}_{v}+\hat{p}_{u}}{2}$, for a risk seeking patient it exceeds $\frac{\hat{p}_{v}+\hat{p}_{u}}{2}$.
} 
Result 5. An increase in risk aversion always leads to an increase in the ex post value of information. ${ }^{8}$

\section{Derivation:}

Suppose that $p<\hat{p}_{u}$ so that patients with utility function $u$ do not take treatment in the absence of diagnostic information. Their expected utility is given by:

$$
I=(1-p) u\left(h_{1}\right)+p u\left(h_{0}\right)=u(\bar{h}-\pi) .
$$

In Eq. (11), $\bar{h}=(1-p) h_{1}+p h_{0}$ is the average health status when no treatment is taken and $\pi$ is the the Arrow-Pratt risk premium when no treatment is taken.

If they perform the test, patients know that they will take treatment in case the test reveals that they are sick. Their utility is then $u\left(h_{0}+b\right)<\left(1-\hat{p}_{u}\right) u\left(h_{1}-c\right)+\hat{p}_{u} u\left(h_{0}+b\right)=$ $\left(1-\hat{p}_{u}\right) u\left(h_{1}\right)+\hat{p}_{u} u\left(h_{0}\right)<(1-p) u\left(h_{1}\right)+p u\left(h_{0}\right)=I$. Let $L$ denote the loss in this situation (measured in QALYs) compared to the situation of no information. $L$ is defined by the following equality:

$$
u\left(h_{0}+b+L\right)=I=u(\bar{h}-\pi)
$$

We thus obtain that $L=\bar{h}-\left(h_{0}+b\right)-\pi$.

If the test shows patients are healthy, they do not take treatment and their utility is $u\left(h_{1}\right)>I$. Denote by $G$ the gain resulting from this situation compared to the absence of information. $G$ is defined by:

$$
u\left(h_{1}-G\right)=I=u(\bar{h}-\pi) .
$$

Therefore, $G=h_{1}-\bar{h}+\pi$.

The ex post value of diagnostic information (EPVDI) is defined by the expected gain minus the expected loss resulting from the test result:

\footnotetext{
${ }^{8}$ Note that this result does not presume that patients are risk averse. It also holds if they are risk seeking or risk neutral and become less risk seeking or risk averse.
} 


$$
E P V D I=(1-p) G-p L=p b+\pi
$$

As more risk averse patients have higher risk premia, Equation (14) shows immediately that the ex post value of diagnostic information increases with risk aversion. The ex post value of diagnostic information is obtained by summing the risk premium and the ex ante value of diagnostic information in the case of risk neutrality (see Eq. (8)). In contrast to the ex ante approach, the test has ex post value for risk averse agents even in the absence of treatment (i.e. if $b=0$ ). This follows because the benefit of removing the risk is included in the ex post approach, but not in the ex ante approach.

A similar line of reasoning can be used when the probability of disease exceeds the treatment threshold $\left(p>\hat{p}_{u}\right)$. Then patients take the treatment in the absence of diagnostic information and their expected utility is equal to:

$$
J=(1-p) u\left(h_{1}-c\right)+p u\left(h_{0}+b\right)=u(\hat{h}-\hat{\pi}) .
$$

In Eq. (15), $\hat{h}=(1-p)\left(h_{1}-c\right)+p\left(h_{0}+b\right)$ is the average health status when treatment is taken and $\hat{\pi}$ is the Arrow-Pratt risk premium when treatment is taken.

Patients know that they will take treatment if the test reveals that they are sick. Their utility is $u\left(h_{0}+b\right)<J$. Let $L^{*}$ denote the loss in this situation compared to the situation of no information.

$$
u\left(h_{0}+b+L^{*}\right)=J=u(\hat{h}-\hat{\pi}) .
$$

Thus $L^{*}=\hat{h}-\left(h_{0}+b\right)-\hat{\pi}$.

If the test shows patients are healthy, they do not take treatment and their utility is $u\left(h_{1}\right)>J$. The welfare gain $G^{*}$ resulting from this situation compared to the absence of information is equal to:

$$
u\left(h_{1}-G^{*}\right)=J=u(\hat{h}-\hat{\pi}) .
$$


Therefore $G^{*}=h_{1}-\hat{h}+\hat{\pi}$.

The ex post value of the diagnostic information is equal to:

$$
E P V D I=(1-p) G^{*}-p L^{*}=(1-p) c+\hat{\pi}
$$

Equation (18) shows that also in the case where treatment is the patient's choice in the absence of a diagnostic test, the ex post value of diagnostic information is the sum of the risk premium and the ex ante value of diagnostic information in the case of risk neutrality (see Eq. (8)). Hence, risk aversion increases the ex post value of diagnostic information also in this case. Equations (14) and (18) jointly prove Result 5.

\section{Conclusion}

The value of information is a widely-used concept in health economics and medical decision making. The literature in decision theory has highlighted the ambiguous effect of risk aversion on the value of information for special cases. A first contribution of our paper is to show in a general model that more risk aversion increases the ex ante value of information when disease prevalence is below a probability threshold and decreases it thereafter. Second, we show that the ex post value of diagnostic information always increases with risk aversion. This follows because the ex post value of information includes not only the benefit of making better informed treatment decisions, but also the benefit of removing the risk. By making the distinction between the ex ante and ex post values of the diagnostic information, we qualify previously derived conclusions in the literature.

There are several ways in which our analysis can be extended. The first one consists in examining empirically our theoretical results. It should be possible to design an experiment or a survey study that collects information about participants' disease prevalence, a test for their risk aversion and to elicit their willingness to obtain information about the disease. A second extension is to consider other models than expected utility, such as prospect theory, in which risk attitudes are probability- 
dependent or models of anxiety (Köszegi 2003). In these models the value of information can be negative. Such extensions can be challenging, because the notions of risk aversion and the value of information are not always uniquely defined in these models, unlike in expected utility theory. A third extension would be to take the probability of diseases as ambiguous. Then Proposition 3 in Maccheroni, Marinacci and Ruffino (2013) could be used to disentangle the effects of risk aversion and ambiguity aversion on the premium $\pi$ in Eq. (3). From there, applying the techniques of section 5 , it might be possible to determine whether the ex post value of diagnostic information increases with risk aversion and with ambiguity aversion. This issue is also left for future research.

\section{References}

Bleichrodt H. and J.L. Pinto, "The validity of QALYs under non-expected utility", The Economic Journal 115(503) (2005), pp. 533-550.

Ebert S., Nocetti D. and H. Schlesinger. "Greater mutual aggravation." Management Science 64(6) (2018), pp. 2809-2811.

Eeckhoudt L., Lebrun T. and J.C. Sailly, "The informative content of diagnostic tests: An economic analysis", Social Science and Medicine, 18(10) (1984), pp. 873-880.

Eeckhoudt L., Lebrun T. and J.C. Sailly. "Risk-aversion and physicians' medical decisionmaking", Journal of Health Economics 4(3) (1985), pp. 273-281.

Eeckhoudt L., "Risk and medical decision making", Kluwer Academic Publishers, Boston, Dordrecht, London (2002).

Eeckhoudt L., Rey, B. and H. Schlesinger. "A good sign for multivariate risk taking", Management Science 53.1 (2007), pp.117-124.

Felder S. and T. Mayrhofer, "Risk preferences: consequences for test and treatment thresholds and optimal cutoffs", Medical Decision Making, 34 (1) (2014), pp. 34-41.

Freixas X. and R. Kihlstrom, "Risk aversion and information demand", in M. Boyer, R. Kihlstrom (Eds.), Bayesian Models of Economic Theory, Elsevier, Amsterdam (1984), pp. 93-104 
Gollier C. and J.W. Pratt, "Risk vulnerability and the tempering effect of background risk", Econometrica, 64(5) (1996), pp. 1109-1123.

Gould J., "Risk, stochastic preference, and the value of information", Journal of Economic Theory, 8 (1974), pp. 64-84.

Hilton R., "The determinants of information value: Synthesizing some general results", Management Science, 27(1) (1981), pp. 57-64.

Jewitt I., "Risk aversion and the choice between risky prospects: the preservation of comparative statics results", Review of Economic Studies, 54 (1987), pp. 73-85.

Kőszegi, B., "Health anxiety and patient behavior." Journal of Health Economics, 22(6) (2003), pp. 1073-1084.

Maccheroni, F., Marinacci, M., \& Ruffino, D., "Alpha as ambiguity: Robust mean-variance portfolio analysis. " Econometrica, 81(3) (2013), pp. 1075-1113.

McNeil, B.J., Weichselbaum, R., and S.G. Pauker, "Tradeoffs between quality and quantity of life in laryngeal cancer", New England Journal of Medicine, 305 (1981), pp. 982-987.

Pauker S. and J. Kassirer, "The threshold approach to clinical decision making", New England Journal of Medicine, 302 (1980), pp. 1109-1117.

Pratt J.W., "Risk aversion in the small and in the large", Econometrica, 32 (1964), pp. 122136.

Sandmo A., "On the theory of the competitive firm under price uncertainty", The American Economic Review, 61(1) (1971), pp. 65-73.

Stiggelbout, A.M., Kiebert, G. M., Kievit, J., Leer, J. W. H., Stoter, G., and J. C. J. M. De Haes, "Utility assessment in cancer patients: adjustment of time tradeoff scores for the utility of life years and comparison with standard gamble scores." Medical Decision Making 14(1) (1994), pp. 82-90.

Willinger M., "Risk aversion and the value of information", The Journal of Risk and Insurance, 56 (1) (1989), pp. 104-112. 